\title{
DECLINING INCIDENCE OF CENTRAL NERVOUS SYSTEM ANOMALIES IN NEW YORK STATE
}

BY

\author{
ALAN M. GITTELSOHN AND SAMUEL MILHAM \\ New York State Department of Health, Albany, New York
}

\begin{abstract}
Anencephalus, spina bifida, and hydrocephalus are the most common of the major structural anomalies of the central nervous system recognizable at birth. Anencephalus is characterized by absence of the cranial vault of the skull. The cerebral hemispheres are completely missing or are reduced to small masses attached to the base of the skull. Spina bifida is a dorsal defect of the vertebral column ranging in severity from minor bony defects, visible only by $x$ ray, to massive clefts of the spinal column. Meningocele, meningomyelocele, and myelocele are part of the same embryological process. Congenital hydrocephalus is characterized by enlargement of the head and separation of the cranial bones caused by abnormal production, circulation, or absorption of the cerebrospinal fluid (Potter, 1952). Spina bifida in the thoracic and upper cervical region is a frequent concomitant of both hydrocephalus and anencephalus. Stevenson (1956) reported that the ArnoldChiari syndrome by itself may be the cause of hydrocephalus, and Penrose (1957) found it to be in frequent association with anencephalus, thereby providing a morphological link between the conditions and justifying concurrent analysis.
\end{abstract}

The mechanisms and aetiologies underlying the production of the three deformities are incompletely understood. Epidemiological studies of incidence have demonstrated the existence of wide geographical variations, the bases of which remain unclear. The markedly increased frequencies of cases in the lower social classes of Scotland (Edwards, 1958), associations with birth order and maternal age (Ingalls, Pugh, and MacMahon, 1954; Record, 1961), and seasonal variations in incidence (Edwards, 1958), are consistent with the operation of environmental causes. The low familial incidence and the discordance between monozygotic and conjoined twins reported by Penrose argue against a simple genetic hypothesis. Few consanguinity studies have been completed. Abnormal karyotypes have not been demonstrated by cytological examination.

All three malformations have been produced in experimental animals through a variety of procedures. Hydrocephalus has been obtained through vitamin A deficiency in rats and rabbits. Folic acid antagonists and vitamin $\mathrm{E}$ deficiency have been reported to lead to hydrocephalus, cranium bifidum, spina bifida, and exencephaly in several species. Giroud and Martinet (1954) reported the production of 54 per cent. anencephalic offspring when female rats were treated with 60,000 IU vitamin A for 3 days beginning with the 8th day of pregnancy. Hyper- and hypothermia and pressure changes have been shown to lead to a variety of central nervous system defects. Kalter and Warkany (1954), in their extensive review, provide a lengthy list of agents which have proved to be teratogenic in experimental situations. The pertinency of these results for man remains to be more thoroughly explored.

The determination of incidence relative to environmental factors and parental characteristics may be of central importance in studies of the aetiology and genetics of any trait. The difficulty of assembling from clinical records case series of sufficient magnitude for analytic purposes and the selection biases inherent in hospital samples would suggest the appropriateness of utilizing demographic methods. Unfortunately, few data are available on the occurrence of congenital malformations in population groups, and no national statistics are published on the frequencies among live and stillbirths. Scotland is the only country for which stillbirths are classified by cause in suitable detail for distinguishing among the most common defects. However, a series restricted to stillbirths is of little value for the study of spina bifida and hydrocephalus and only partially adequate for anencephalus which is not compatible with postnatal life beyond a few hours or days. Neonatal and infant 
death records provide a secondary source of information which becomes useful when the data are matched to corresponding birth records and pregnancy histories.

The present communication is concerned with the recorded incidence of major malformations of the central nervous system among $2 \cdot 5$ million births produced by residents of Upper New York State during the period 1945 through 1959. It describes the malformations recognized at birth in foetuses born alive and born dead after the 20th week of pregnancy. Variations in incidence for New York are found to be consistent with those reported for Rhode Island (Ingalls, Pugh, and MacMahon, 1954), for Scotland (Edwards, 1958; Record, 1961), and for Birmingham (Record and McKeown, 1949). The most striking observations are the declining incidence rates of anencephalus, spina bifida, and hydrocephalus, each having decreased by over 50 per cent. during the 15-year period.

\section{Method of Ascertainment}

For two decades the New York State birth certificate has contained an entry for recording congenital malformations. The entry is completed with a negative response or with notation of specific defects on over 90 per cent. of the certificates. The data analysed herein relate to live births and stillbirths with at least one malformation of the central nervous system and to deaths of children under 5 years of age attributed to central nervous system malformations, the population at risk being all births occurring to residents of Upper New York State between 1945 and 1959 (Upper New York includes the entire State with the exception of New York City). All birth, death, and stillbirth certificates noting central nervous system anomalies were reviewed and coded.

The problem of incomplete ascertainment of cases in a study based on routine records completed in numerous institutions is a central one. Anencephalus has been recognized and described for centuries and its appearance is so marked that it is unlikely not to be noted. Undoubtedly, a certain number of cases are not recorded on the birth record and others are classified as monsters and are thereby lost. However, the latter category is of comparatively low frequency amounting to less than 10 per cent. of the anencephalic group (Table II, opposite). It is reasonable that the more severe forms of spina bifida would more likely be noted than the less severe and occult forms. As a check on birth certificate reporting, a series of 99 cases receiving treatment for the defect under the State programme was located and traced back to the birth records. All but fourteen had notation of the condition on the birth certificate. This is an overstatement of the under-reporting, as the case series includes a larger proportion of the less severe forms than the total group born with the defect. Hydrocephalus presents a special problem because it may be postnatal in origin. For the most part, the severe congenital cases are stillborn. The less severe cases and those developing after birth have poor viability and are subject to ascertainment through death records. The neural tube anomalies under discussion, unlike many other structural malformations of interest, are recognizable at birth, and are generally not compatible with post-natal existence, and thus are subject to ascertainment through efficient vital registration systems. The major failing of such systems lies in the absent or incomplete data on abortions.

\section{RESULTS}

\section{Total Cases and Survivorship}

During the 15-year period between 1945 and 1959, a total of 8,295 births were reported to have one or more malformations of the central nervous system among 2,552,910 births of more than 20 weeks gestation occurring to residents of Upper New York State. Spina bifida, which includes meningocele, meningomyelocele, and myelocele, is the most frequent defect with 3,021 cases representing an average rate of 118 per 100,000 births (see Table I). A total of 730 cases with both spina bifida and hydrocephalus are included in the latter group. The next most common conditions are anencephalus and hydrocephalus with 2,205 and 2,137 cases respectively. The remaining central nervous system malformations comprise less than 12 per cent. of the total. Included here are such diverse entities as cyclops, microcephalus, aplasia of the brain, agenesis and dysgenesis of the eye, congenital cataract, and monster.

TABLE I

MALFORMATIONS OF THE CENTRAL NERVOUS SYSTEM AT BIRTH, BY TYPE AND BY SURVIVORSHIP Upper New York State, 1945-1959

\begin{tabular}{|c|c|c|c|c|c|c|}
\hline \multicolumn{3}{|c|}{ CNS Malformations } & $\begin{array}{l}\text { Anen- } \\
\text { cephalus }\end{array}$ & $\begin{array}{l}\text { Spina } \\
\text { Bifida }\end{array}$ & $\begin{array}{l}\text { Hydro- } \\
\text { cephalus }\end{array}$ & Other \\
\hline \multicolumn{3}{|c|}{$\begin{array}{ccc}\text { Total Births with CNS Mal- } \\
\text { formations . } & \ldots & \ldots \\
\end{array}$} & 2,205 & 3,021 & 2,137 & 932 \\
\hline \multicolumn{2}{|c|}{ Stillbirths } & $\ldots$ & 1,430 & 463 & 1,251 & 342 \\
\hline \multirow{3}{*}{$\begin{array}{l}\text { Live } \\
\text { born }\end{array}$} & \multicolumn{2}{|l|}{ Total } & 775 & 2,558 & 886 & 590 \\
\hline & Died & $\begin{array}{l}\text { 1st day } \\
\text { 2nd-27th day } \\
1-11 \text { mths } \ldots \\
1-4 \text { yrs } \quad \ldots\end{array}$ & $\begin{array}{r}647 \\
102 \\
9 \\
3\end{array}$ & $\begin{array}{l}447 \\
487 \\
748 \\
113\end{array}$ & $\begin{array}{l}278 \\
115 \\
257 \\
107\end{array}$ & $\begin{array}{r}100 \\
188 \\
89 \\
48\end{array}$ \\
\hline & \multicolumn{2}{|c|}{$\begin{array}{cc}\text { Not known dead at } \\
5 \text { yrs }\end{array}$} & 14 & 763 & 129 & 165 \\
\hline
\end{tabular}


For the three major central nervous system defects, marked differences in survivorship are to be noted. Nearly two-thirds of the anencephalics are stillborn, as contrasted with 15 per cent. of the spina bifida cases and about 60 per cent. of the hydrocephalus cases. Record (1961) reported that less than 5 per cent. of the Scottish anencephaly cases were born alive, a difference perhaps related to variation in definition and interpretation of signs of life at birth in the two countries. The majority of live born anencephalus cases die within the first day after birth; 5 years after birth, fourteen of the 2,205 anencephalics are classified as being "not known dead", a circumstance more likely due to initial misclassification or to inability to trace the cases than actual survival. The 5-year survival for spina bifida is about one-third, and for hydrocephalus 6 per cent.

At the time of writing, a slight error is included in the latest 3 years of the study because of incompleteness of 5-year follow-up. On the average, 21 years have elapsed for the 1959 events, 31 for the 1958 events, and 41 for the 1957 events. The error can be disregarded for anencephalus and is estimated to be less than 0.5 per cent. for both spina bifida and hydrocephalus on the basis of previous years' experience.

\section{RACE AND SeX}

Table II and Fig. 1 show the incidence of central nervous system malformations by race and sex. As has been noted by other investigators, anencephalus is two to three times more common among females than males. Based on stillbirths alone, the ratio of male to female case rates is 0.39 to 1.0 , while for the live born case rates the ratio is 0.65 to $1 \cdot 0$. As still-
TABLE II

INCIDENCE OF CENTRAL NERVOUS SYSTEM MALFORMATIONS, BY RACE AND SEX, UPPER NEW YORK STATE, 1945-59

\begin{tabular}{|c|c|c|c|c|c|c|c|}
\hline \multirow{2}{*}{$\begin{array}{l}\text { Race } \\
\text { Sex }\end{array}$} & \multirow{2}{*}{$\begin{array}{ccc} & \cdots & \cdots \\
& \ldots & \ldots\end{array}$} & \multicolumn{3}{|c|}{ White } & \multicolumn{3}{|c|}{ Non-White } \\
\hline & & Total* & Male. & $\begin{array}{c}\mathrm{Fe}- \\
\text { male }\end{array}$ & Total* & \multirow{2}{*}{$\frac{\text { Male }}{52}$} & $\begin{array}{c}\mathrm{Fe}- \\
\text { male }\end{array}$ \\
\hline \multicolumn{2}{|c|}{ Total Births $(1,000 \mathrm{~s})$} & 2,451 & 1,259 & 1,192 & 102 & & 50 \\
\hline \multirow{6}{*}{$\begin{array}{c}\text { No. } \\
\text { of } \\
\text { Cases }\end{array}$} & Total & 8,109 & 3,488 & 4,587 & 186 & 87 & 99 \\
\hline & \multirow{3}{*}{$\begin{array}{l}\text { Anencephalus } \\
\text { Spina bifida } \\
\text { Hydrocephalus } \\
\text { Microcephalus } \\
\text { Eye agenesis, } \\
\text { dysgenesis } \\
\text { Cataract } \\
\text { Other Central } \\
\text { Nervous } \\
\text { System mal- } \\
\text { formations }\end{array}$} & $\begin{array}{r}2,167 \\
2,979 \\
2,063 \\
230\end{array}$ & $\begin{array}{r}683 \\
1,287 \\
1,130 \\
80\end{array}$ & $\begin{array}{r}1,478 \\
1,684 \\
927 \\
150\end{array}$ & $\begin{array}{r}38 \\
42 \\
74 \\
7\end{array}$ & $\begin{array}{r}21 \\
17 \\
36 \\
3\end{array}$ & $\begin{array}{r}17 \\
25 \\
38 \\
4\end{array}$ \\
\hline & & $\begin{array}{r}125 \\
54\end{array}$ & $\begin{array}{l}54 \\
33\end{array}$ & 71 & 6 & 4 & 2 \\
\hline & & 491 & 221 & 256 & 18 & 5 & 13 \\
\hline & \multirow{2}{*}{$\begin{array}{l}\text { Monster } \\
\text { Aplasia of } \\
\text { brain }\end{array}$} & 211 & 94 & 105 & 4 & 2 & 2 \\
\hline & & 232 & 118 & 114 & 12 & 3 & 9 \\
\hline \multirow{6}{*}{$\begin{array}{c}\text { Cases } \\
\text { per } \\
100,000 \\
\text { Births }\end{array}$} & Total & 331 & 277 & 385 & 182 & 167 & 198 \\
\hline & \multirow{5}{*}{$\begin{array}{l}\text { Anencephalus } \\
\text { Spina bifida } \\
\text { Hydrocephalus } \\
\text { Microcephalus } \\
\text { Eye agenesis, } \\
\text { dysgenesis } \\
\text { Other Central } \\
\text { Nervous } \\
\text { System mal- } \\
\text { formations }\end{array}$} & 88 & 54 & 124 & 37 & 40 & 34 \\
\hline & & 84 & 90 & $\begin{array}{r}141 \\
78\end{array}$ & 73 & 69 & 77 \\
\hline & & 0 & & 13 & & 0 & \\
\hline & & 5 & 4 & 6 & 6 & 6 & 4 \\
\hline & & 20 & 18 & 21 & 18 & 10 & 26 \\
\hline
\end{tabular}

*Includes cases with sex not stated.

births have a shorter mean gestation period than live births, this is in accord with the finding of an increasing sex ratio with increasing length of gestation (Ingalls, Pugh, and MacMahon, 1954). For nonwhites (predominantly Negro), there is a slight male excess (1.18 males to 1.00 females) which is based on 38 cases of anencephalus among 101,837 live and
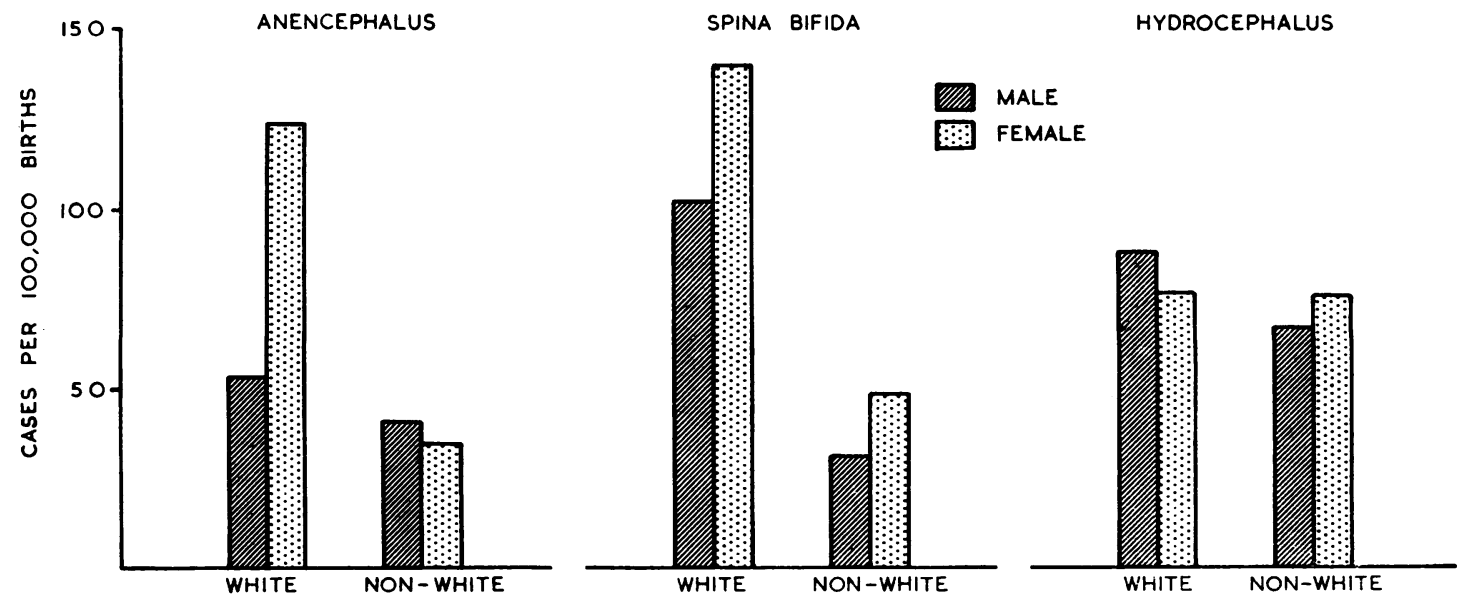

Fig. 1.-Incidence of Central Nervous System Malformations by Race and Sex, in Upper New York State, 1945-1959 
stillbirths and represents a highly significant statistical deviation from the sex ratio of all cases disregarding race $(p<\cdot 01)$. The underlying bases of the female predominance among whites and the male predominance among non-whites are not understood. The sex ratio of spina bifida cases is about 4 to 3 in favour of females, a pattern holding true for both race groups. There is a male excess among white hydrocephalics (90 male to 78 female cases per 100,000 births), while for non-whites the sex ratio is significantly lower, about $0.90(p<\cdot 01)$.

A number of writers have reported that American Negroes experience a low incidence of congenital malformations of the central nervous system. This is substantiated in the present New York data where anencephalus and spina bifida are two and three times more common among whites than non-whites. For hydrocephalus, the race difference is less apparent, there being a small difference between white and non-white male case rates and no difference between the two female rates. The basis for variations in incidence by race may be genetic or environmental or an interaction of both and, until further information is produced, must remain a matter for speculation.

\section{GeOgraphical Variations}

The survey of the literature by Penrose (1957) reveals the existence of wide geographical variations in the incidence of anencephalus. Generally, case rates are below 100 per 100,000 births, the upper extreme of nearly 700 being recorded for parts of the British Isles. For the most part, the rates are based on hospital deliveries and tend to be overstatements of the actual population incidence. In 1957, the rate for two Belfast hospitals was 679 as contrasted with a rate of 458 for all pregnancies terminating in the city during the year (Stevenson and Warnock, 1959). The greater likelihood of complicated pregnancies being hospitalized may underlie this difference. In New York, virtually all deliveries occur in hospitals ( 99.4 per cent.), and this type of selection bias is avoided. Table III presents population incidence data for New York and Scotland. The Scottish anencephalic rates are based on stillbirths alone and thus understate occurrence by at least 5 per cent. The Scottish spina bifida and hydrocephalus rates include both stillbirths and infant deaths and understate incidence by not including the survivors past one year.

Anencephalus incidence varies between 60 and 300 , the maximum and minimum rates being recorded in Scotland and New York during the 19551959 quinquennium. The Japanese and Dutch population rates reported by Penrose are comparable with
TABLE III

INCIDENCE OF ANENCEPHALUS, SPINA BIFIDA AND HYDROCEPHALUS IN NEW YORK AND SCOTLAND

\begin{tabular}{|c|c|c|c|c|c|c|}
\hline \multirow{2}{*}{\multicolumn{2}{|c|}{ Region }} & \multirow{2}{*}{ Year } & \multirow{2}{*}{$\begin{array}{c}\text { Total } \\
\text { Births } \\
(1,000 s)\end{array}$} & \multicolumn{3}{|c|}{$\begin{array}{c}\text { Malformations per } \\
100,000 \text { Births }\end{array}$} \\
\hline & & & & $\begin{array}{l}\text { Anen- } \\
\text { cephalus }\end{array}$ & $\begin{array}{l}\text { Spina } \\
\text { Bifida }\end{array}$ & $\begin{array}{l}\text { Hydro- } \\
\text { cephalus }\end{array}$ \\
\hline \multirow{4}{*}{$\begin{array}{l}\text { Upper } \\
\text { New } \\
\text { York } \\
\text { State }\end{array}$} & Total . . & 1945-59 & 2,553 & 86 & 118 & 83 \\
\hline & $\begin{array}{l}\text { Western } \\
\text { Region }\end{array}$ & $\begin{array}{r}1945-49 \\
1950-54 \\
1955-59\end{array}$ & $\begin{array}{l}266 \\
301 \\
339\end{array}$ & $\begin{array}{r}110 \\
75 \\
60\end{array}$ & $\begin{array}{r}160 \\
117 \\
80\end{array}$ & $\begin{array}{r}101 \\
86 \\
66\end{array}$ \\
\hline & $\begin{array}{c}\text { Southern } \\
\text { Region }\end{array}$ & $\begin{array}{l}1945-49 \\
1950-54 \\
1955-59\end{array}$ & $\begin{array}{l}328 \\
424 \\
523\end{array}$ & $\begin{array}{r}100 \\
74 \\
64\end{array}$ & $\begin{array}{r}144 \\
102 \\
81\end{array}$ & $\begin{array}{r}105 \\
77 \\
59\end{array}$ \\
\hline & $\begin{array}{r}\text { Northern } \\
\text { Region }\end{array}$ & $\begin{array}{l}1945-49 \\
1950-54 \\
1955-59\end{array}$ & $\begin{array}{l}116 \\
123 \\
133\end{array}$ & $\begin{array}{r}166 \\
121 \\
89\end{array}$ & $\begin{array}{l}212 \\
158 \\
106\end{array}$ & $\begin{array}{r}140 \\
118 \\
89\end{array}$ \\
\hline \multicolumn{2}{|c|}{$\begin{array}{l}\text { Scotland } \\
\text { (Registrar- } \\
\text { General) }\end{array}$} & $\begin{array}{l}1945-49 \\
1950-54 \\
1955-59\end{array}$ & $\begin{array}{l}515 \\
469 \\
497\end{array}$ & $\begin{array}{l}233 \\
267 \\
295\end{array}$ & $\begin{array}{l}162 \\
174 \\
165\end{array}$ & $\begin{array}{l}221 \\
196 \\
181\end{array}$ \\
\hline
\end{tabular}

those for New York. Spina bifida rates range between 80 and 200 and hydrocephalus rates between 60 and 220. Because of the different methods of ascertainment, the Scottish rates are understatements relative to the New York rates. The recorded differences in incidence of five-fold for hydrocephalus are probably conservative estimates of the actual differences between the two countries. By themselves, such variations provide no suggestions as to the diverse influences which may be operating.

\section{TRENDS}

During the 15 -year study period, there has been a consistent and rapid decline in the incidence of all three major malformations of the central nervous system in New York State (Fig. 2, opposite). For anencephalus, the rate has dropped from a high point of 123 cases per 100,000 births in 1946 to a low point of 60 in 1959. This decline of over 50 per cent. is to be contrasted with the experience in Scotland where the anencephalic stillbirth rate has increased by 50 per cent. in the past decade. It is highly unlikely that such gross changes over short periods of time reflect an anomaly of the reporting. The declining incidence in New York has occurred during a time of increasing interest in and awareness of the importance of the congenital malformation problem. Over 99 per cent. of all New York births occur in hospitals and the birth certificates are filled in from the medical records. Each of the 57 counties in the State of New York has exhibited a declining rate during the period.

Spina bifida case rates in New York have dropped from 192 in 1945 to 83 in 1959, representing a decline of nearly 60 per cent. in the 15 years. With the exception of four minor inversions, the secular trend has 

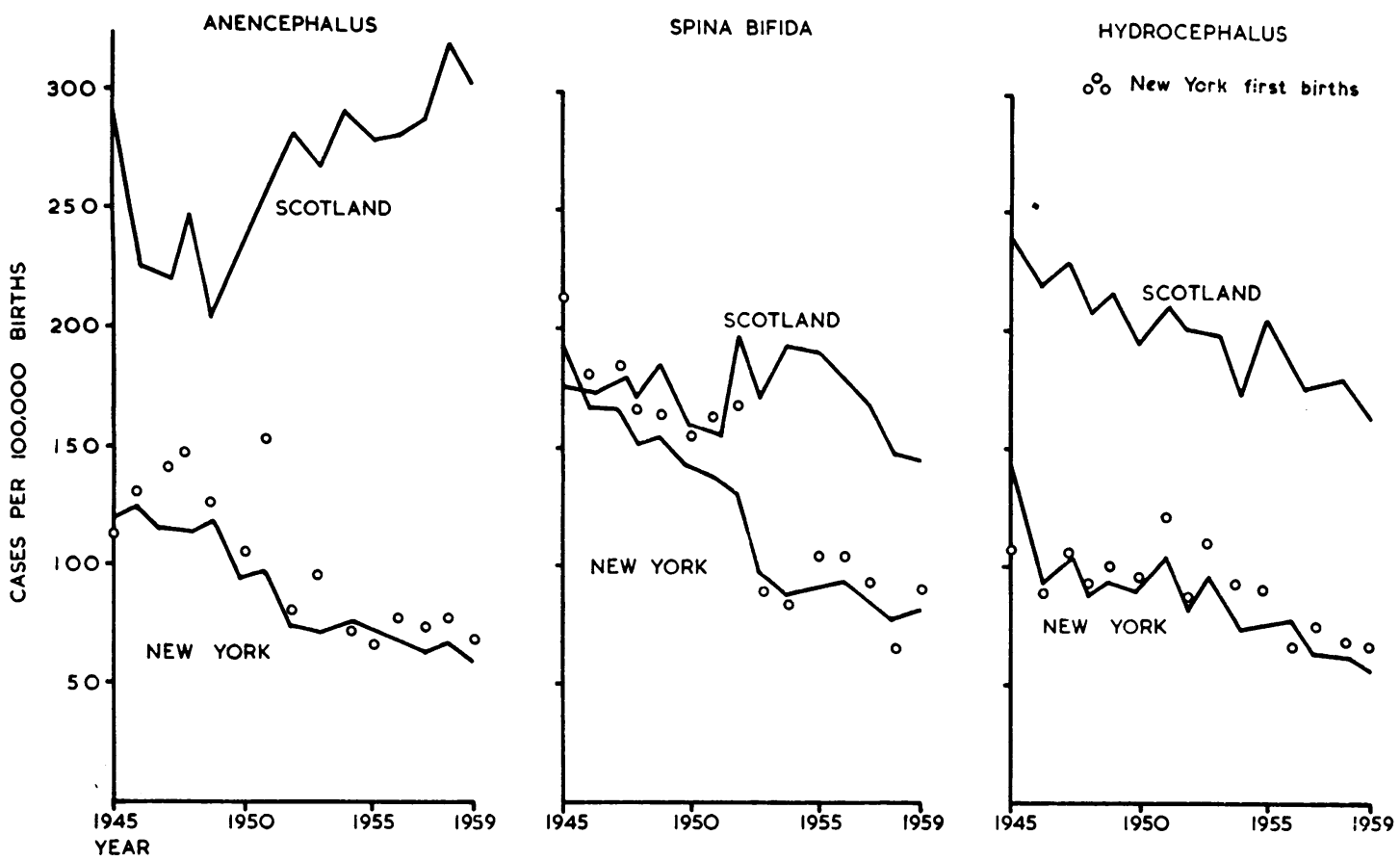

Fig. 2.-Trends in the Incidence of Major Malformations of the Central Nervous System, in Scotland and Upper New York State, 1945-1959.*

* Scotland: Anencephalus incidence rates based on stillbirths only. Spina bifida and hydrocephalus rates based on stillbirths and infant deaths. New York: Incidence rates based on live and stillbirths and deaths of children under 5 years of age.

been consistently downward. Spina bifida stillbirth and infant death rates from reports of the Registrar General for Scotland (1945-59) covering the same period exhibit irregular variations between 150 and 200 cases per 100,000 births and a relatively slight downward trend since 1954.

Hydrocephalus incidence in New York has dropped 60 per cent. from a high point of 141 in 1945 to a low point of 57 in 1959. This decline has been marked by greater irregularity than that of either anencephalus or spina bifida. The hydrocephalus rates for Scotland have dropped by about one-third during the same period.

The effects of parity and maternal age on the incidence of the three defects have been noted by several investigators (Potter, 1952; Ingalls, Pugh, and MacMahon, 1954; Penrose, 1957; Edwards, 1958). The changing proportion of first births and the varying average maternal age during the study period suggests the desirability of adjusting the annual rates for these factors. Such a procedure has a minor effect on the downward trends and does not alter the pattern of consistent reduction of more than 50 per cent. for each of the three major central nervous system malformations between 1945 and
1959. Incidence relative to birth order and maternal age will be treated in more detail in a later communication.

The incidence of anencephalus, spina bifida, and hydrocephalus shows a distinct geographical distribution throughout the State. The range in incidence by county varies by a factor of more than four. Generally, the densely-populated urban and suburban counties have low rates and the areas with high rates are rural or mountainous. The highest concentration of all three types of cases is to be found in the northern Adirondack Mountains and the adjoining St. Lawrence River Valley on the northern border of New York State. All areas of the State have experienced consistent and sharp declines in the incidence of each of the malformations. This has led to a diminution of geographic differences during the latter part of the study period (Table III).

\section{Discussion}

As with the great majority of congenital malformations, no specific causal factor has been demonstrated for the neural tube defects being considered. A given morphological entity may represent the 
operation of diverse influences and may have as its basis several distinct aetiologies. From the end result, it may be impossible to sort out the particular factor or combination of factors responsible for the defect in any one case. Today, it is common to speak of congenital malformations as the result of "complex interactions between multi-factorial genetic and environmental systems" (Fraser, 1959).

Only tentative inferences can be drawn from the population incidence data presented. The existence of race, sex, and geographical variations has been confirmed, but their bases remain unknown. The rapidly declining incidence of the three major malformations of the central nervous system casts doubt on certain hypotheses currently being entertained. The 15-year period for which the trend has been measured is so short as to make unlikely the operation of factors as predominant causes which remain fairly constant in the environment; i.e.-cosmic and background radiation and certain meteorological variables. Similarly, without additional information not contained in vital records, it is difficult to reconcile a simple genetic explanation with such dramatic, short-term changes in incidence. The pattern is more consistent with the operation of varying environmental influences.

\section{SUMmary}

(1) Vital records of all children with one or more malformations of the central nervous system born to Upper New York State residents during the years 1945-1959 have been collected and tabulated. Case rates have been computed on the basis of the total population of births so defined.

(2) Race, sex, and geographical variations in incidence have been noted and discussed.

(3) The incidence of anencephalus, spina bifida, and hydrocephalus in New York has declined by over 50 per cent. during the 15 years and the significance of this decline has been considered.

This study was supported in part by a training grant (2G-558) from the National Institutes of Health, United States Public Health Service.

\section{REFERENCES}

Annual Reports of the Registrar-General for Scotland, 1945-1959, Nos. 91-105 (1947-60). H.M.S.O., Edinburgh.

Edwards, J. H. (1958). Brit. J. prev. soc. Med., 12, 115.

Fraser, F. C. (1959). J. chron. Dis., 10, 97.

Giroud, A., and Martinet, M. (1954). C. R. Soc. Biol., 148, 1742 .

Ingalls, T. H., Pugh, T. F., and MacMahon, B. (1954). Brit. J. prev. soc. Med., 8, 17.

Kalter, H., and Warkany, J. (1959). Physiol. Rev., 39, 69.

Penrose, L. S. (1957). J. ment. Def. Res., 1, 4.

Potter, E. L. (1952). "Pathology of the Fetus and the Newborn". Year Book Publishers, Chicago.

Record, R. G. (1961). Brit. J. prev. soc. Med., $15,93$. and McKeown, T. (1949). lbid., 3, 183.

Stevenson, A. C. (1956). Ulster med. J., 25, 101. 382. 